DOI: $10.1177 / 09637214211070814$

Miyake, Kane

Current Directions in Psychological Science 31(4)

\title{
Toward a Holistic Approach to Reducing Academic Procrastination With Classroom Interventions
}

\author{
Akira Miyake ${ }^{1}$ and Michael J. Kane ${ }^{2}$
}

1Department of Psychology and Neuroscience, University of Colorado Boulder, and

2Department of Psychology, University of North Carolina at Greensboro

Current Directions in Psychological Science

This version reflects all the changes made during the copy-editing stage

The final published version of this article (open access) is available at:

https://doi.org/10.1177/09637214211070814

\author{
Corresponding Author \\ Akira Miyake \\ Department of Psychology and Neuroscience \\ University of Colorado Boulder \\ Email: akira.miyake@colorado.edu \\ Transparency \\ Action Editor: Robert L. Goldstone \\ Editor: Robert L. Goldstone
}

Declaration of Conflicting Interests

The author(s) declared that there were no conflicts of interest with respect to the authorship or the publication of this article.

\section{ORCID ID}

Akira Miyake https://orcid.org/0000-0003-4671-7843

\section{Acknowledgments}

We thank Bekah Benjamin-Pollak, Dan Gustavson, Lisa Muschinski, Priti Shah, Frode Svartdal, Lei Yuan, and Han Zhang for providing useful feedback on an earlier version of this article. The ideas presented in this article are an extension of a brief presentation we gave at an online procrastination workshop (July 2021). We thank the participants at the workshop for useful feedback on our ideas.

\footnotetext{
Abstract

Although academic procrastination is prevalent, few interventions targeting it have been rigorously tested. We propose a novel approach to developing effective classroom interventions for academic procrastination, based on the ideas that changing complex behaviors requires a holistic, multipronged approach and that intervention research must embrace objective measures of procrastination behavior. We illustrate what such intervention efforts may look like by deriving some easily implementable techniques from a simple process model of self-control, which characterizes procrastination as a goal-management failure resulting from a need to repair negative emotion triggered by impending academic tasks.

Keywords: academic procrastination, classroom intervention, holistic approach, self-control, emotion regulation, open science
} 
Academic procrastination - the voluntary and irrational delay of taking action on academic tasks despite expecting negative consequences of that delay-is common; in fact, $50 \%$ to $75 \%$ of students report procrastinating moderately or severely (e.g., Steel, 2007). Despite such prevalence, students and instructors often regard academic procrastination as innocuous if deadlines are met.

Procrastination appears to have serious consequences, however, for both students' achievement and their well-being. To reduce procrastination, it is important to understand who is especially vulnerable to procrastination, under what conditions, and what factors and processes contribute to procrastination. We address these questions primarily in the context of academic procrastination and argue that it is time for concerted efforts to develop effective interventions that can be efficiently implemented by instructors in classroom settings.

\section{What Is Known About Procrastination}

Current understanding of the predictors and consequences of procrastination comes from a substantial literature based primarily on questionnaires.

\section{General procrastination: predictors and consequences}

The tendency to procrastinate is stable and traitlike; behavior-genetic (twin) research indicates that about half of the population variability in self-reported procrastination is accounted for by genetic factors (Gustavson et al., 2014). Procrastination also generalizes across contexts (Steel, 2007): People who procrastinate in one life domain (e.g., health) also tend to procrastinate in others (e.g., academics). Of course, this generality is imperfect; some people procrastinate more in some domains than in others (Klingsieck, 2013), according to their longstanding interests and values.

The strongest personality-related predictors of procrastination reflect aspects of self-regulation: conscientiousness and impulsivity. More conscientious (more self-disciplined, more cautious) individuals report less procrastination, and more impulsive (more rash, less deliberate) individuals report more procrastination. Other personality correlates of procrastination, such as perfectionism, typically show weaker associations (Steel, 2007). Beyond personality, executive-function abilities to regulate thoughts and actions are also associated with procrastination—albeit weakly (Gustavson et al., 2015).

Procrastination tendencies predict many life outcomes: People who report more procrastination tend to also have poorer physical and mental health, more financial problems, and lower life satisfaction (e.g., Beutel et al., 2016). However, because these relationships are correlational, and because procrastination and life outcomes have typically been assessed simultaneously, one cannot distinguish cause from effect. It is nonetheless plausible that small instances of procrastination (e.g., avoiding a doctor's visit) can have significant consequences (e.g., detecting cancer late).

\section{Academic procrastination: predictors and consequences}

Given the traitlike stability of procrastination, it is unsurprising that academic procrastination correlates with general procrastination, and that conscientiousness and impulsivity are two of its strongest predictors. For example, in our group's recent work, we found that self-reported academic procrastination in university students correlated strongly with general procrastination $(r=.80)$, conscientiousness $(r=-.66)$, and impulsivity $(r=.59$; Benjamin-Pollak et al., 2022, $N=543)$.

What are potential consequences of academic procrastination? A meta-analysis (Kim \& Seo, 2015) indicates that higher self-reported procrastination is associated with lower academic achievement. The associations are significant but weak for global measures, such as grade-point average $(r=-.12,17$ studies, $N=5,390)$, but stronger for outcomes that are specific to the courses in which procrastination is assessed, such as final grade ( $r=-.24,28$ studies, $N=25,847)$.

Academic procrastination also predicts students' self-reported stress. For example, Tice and Baumeister (1997) demonstrated that procrastinators' stress levels increase substantially over the course of a semester, whereas those of nonprocrastinators do not. A study conducted during the COVID-19 pandemic (Peixoto et al., 2021, $N=416$ ) showed that greater academic procrastination predicted greater psychological distress (e.g., stress, depression, anxiety; $r=.34)$ and lower life satisfaction $(r=-.37)$ among university students.

Again, causality is ambiguous, but these associations suggest that academic procrastination is unlikely to be an innocuous quirk without consequences. We further speculate that reducing procrastination should also 
improve students' learning: Although effective study strategies, such as spaced learning and retrieval practice, are well known (e.g., Dunlosky et al., 2013), using them requires adequate implementation time. Procrastinators likely must resort to bad study habits (e.g., cramming) even when intending to study effectively.

\section{Models of Procrastination}

Although several theories of procrastination could drive intervention efforts (e.g., Krause \& Freund, 2014; Zhang \& Feng, 2020), we focus on two complementary models here.

\section{Temporal motivation theory}

The central tenet of Steel's (2011) temporal motivation theory is that one's motivation to work on a task depends on four factors:

$$
\text { motivation }=\frac{\text { expectancy } \times \text { value }}{\text { impulsiveness } \times \text { delay }}
$$

According to this "procrastination equation," the more confidence one has in one's ability to achieve an expected outcome (expectancy) and the more valued that outcome (value), the less likely one is to procrastinate. Even if the outcome matters greatly and seems achievable, one might still put off the task if the deadline is not imminent (delay), especially if one is impulsive (impulsiveness).

This model is broadly applicable to different situations and is consistent with various evidence (e.g., Steel, 2007, 2011; Steel et al., 2018). Also, it suggests general directions for developing intervention strategies for academic procrastination-essentially, seeking to somehow increase expectancy and value and decrease impulsiveness and delay.

\section{A process (self-control) model of procrastination}

The model that we focus on accepts the four contributing factors to procrastination specified in Steel's (2011) model. It is more closely linked, however, to the self-control literature and pinpoints specific yet prevalent processes leading students to procrastinate. Accordingly, this model, although limited in scope, complements rather than competes with Steel's.

This process model proposes two primary causes of procrastination. The first proposed cause-task-induced negative moods - is based on the idea that procrastination is an emotion-regulation process, an idea articulated by Sirois and Pychyl (2013) in their temporal mood-repair theory. Specifically, thoughts of performing an academic task can trigger negative affect ("Ugh, I dread this"), especially if the task is aversive ("I dislike writing papers"). Whether such negative emotions are mild (e.g., boredom, reluctance) or intense (e.g., demoralization, anxiety), they motivate the person to seek more immediately pleasurable activities.

This first cause often triggers the second hypothesized cause, goal-management failure, because attempts to repair negative mood create conflict between two goals: temporarily improving mood (e.g., playing a video game) and accomplishing something of longer-term meaning (e.g., writing a paper to earn a good grade). This self-control dilemma often gets resolved in favor of immediate pleasure over long-term goals_- "giving in to feel good" (Tice \& Bratslavsky, 2000)—especially in the case of distant deadlines and impulsive individuals, who poorly regulate their urges (delay and impulsiveness, respectively, in Steel's, 2011, model).

Although this process model is simple (even simplistic) and postulates only two primary causes of procrastination, it nonetheless provides a useful basis for designing interventions (i.e., interventions should target these causes). Moreover, the model is easy to explain to instructors and students, and students resonate to it. This potential buy-in from both instructors and students is an important component of our proposed intervention program for academic procrastination.

\section{Supporting evidence for the process model}

Evidence for these two hypothesized causes of procrastination is often indirect because mood changes and goal-management failures are hard to observe in everyday situations as they occur. Despite this limitation, research findings are generally consistent with the model, and we provide examples below.

Negative moods. The association between general procrastination and addictive smartphone use-a common source of immediate pleasure — can be partially accounted for by stress levels (Yang et al., 2019). Moreover, a prospective study found that low positive affect partially explained the association between trait procrastination and the time students later spent procrastinating on academic tasks in the presence of social 
temptations (Sirois \& Giguère, 2018). In an experimental study, students induced into a bad mood procrastinated more on a boring math task than did those in a positive mood if they were allowed to change their mood via access to a fun alternative task (Tice et al., 2001).

Goal-management failures. Impulsivity may strongly predict procrastination because both involve goal management: Avoiding impulsive actions and avoiding procrastination both require pursuing long-term goals over short-term pleasure. Indeed, Gustavson et al. (2014) showed that $74 \%$ of the individual-differences overlap between impulsivity and general procrastination is accounted for by measures of goal failures (e.g., easily forgetting a goal). This relationship also holds for self-report measures of academic procrastination: In a recent study from our group, impulsivity and goal failures jointly accounted for $37 \%$ of the variance in academic procrastination, and more than half of that variation $(19 \%)$ was attributable to their shared variance (BenjaminPollak et al., 2022). Finally, Gustavson et al. (2015) showed that the individual-differences overlap between general procrastination and goal failures was predicted by the variance shared across different types of executive functions (inhibition, shifting, and updating), which is considered to reflect goal-management abilities (Miyake \& Friedman, 2012).

\section{Procrastination Interventions}

Despite the prevalence of academic procrastination and the benefits of reducing it, evidence for intervention success is scarce and inconclusive. In a meta-analysis that included intervention studies targeting academic procrastination (van Eerde \& Klingsieck, 2018), only 44 studies $(N=1,173)$ met the inclusion criteria. After studies lacking a control condition were excluded — a must for rigorous research — the overall effect size of intervention effectiveness was moderate and significant $(d=-0.62,35$ studies), and interventions based on cognitive behavioral therapy (11 studies) yielded the strongest effects. These results must be interpreted cautiously, however, because the sample sizes of many studies were small (often $n<20$ per condition) and there was some evidence of publication bias against null findings, which suggests that effect sizes were likely overestimated.

A narrative review of academic-procrastination interventions (Zacks \& Hen, 2018), which also noted that therapeutic prevention and treatment have been common approaches, similarly concluded, "A review of the literature offers scant examples of effective interventions for academic procrastination. ... [M] any studies fall short by not offering randomized control trials and/or validated outcome measures" (p. 122). Further intervention research on academic procrastination is clearly needed.

One might conclude that the most promising approach to procrastination interventions is therapy based, given the results of van Eerde and Klingsieck's (2018) meta-analysis, and given typical intervention approaches to other self-regulation problems (e.g., drug addiction and problem gambling). Indeed, some researchers have suggested adopting a personalized intervention approach in which therapies are selected on the basis of personality types (Steel \& Klingsieck, 2016). We concur that therapy-based approaches merit further research, but suggest that they should be tested with more rigorous methods and larger sample sizes.

A substantial drawback of therapy-based interventions for academic procrastination, however, is that they require individual or small-group settings and guidance by qualified therapists, so they cannot be readily implemented by most classroom instructors. Therefore, we advocate for a promising yet rarely adopted approach, instructor-based intervention (Zacks \& Hen, 2018), which entails instructors modifying their teaching practices to include nontherapeutic methods of preventing academic procrastination. Concrete examples of this approach include encouraging regular study by strategically timing access to study materials (Perrin et al., 2011) or sending students timely and well-crafted reminders about forthcoming deadlines (Huang et al., 2021). Following best practices for "what works" in prevention science (Nation et al., 2003), we advocate for instructor-based interventions that take a holistic, comprehensive approach, as described below.

\section{A Novel Approach to Academic-Procrastination Interventions}

The complexity of academic procrastination requires a broad, multifaceted strategy and the engagement of not only researchers but also instructors and students. The guiding principles of our proposed approach, described in Table 1, are built on this central idea. In this section, we briefly note several principles and then discuss the remaining three (Principles 4, 5, and 7) in more detail.

\section{[Insert Table 1 about here.]}


Instead of being conducted in contrived laboratory settings (commonly used for convenience), intervention studies should be conducted in authentic classroom contexts, where the stakes and challenges are significant, and students share common goals (Principle 1). Intervention studies should also be conducted over extended periods (e.g., 15-week semesters) rather than short durations (e.g., 2 weeks), so that students are likely to encounter temptations to procrastinate and are encouraged to repeatedly practice procrastination-reducing strategies (Principle 2). Moreover, we advocate focusing on small changes that instructors can easily adopt (Principle 3), a principle from Lang's (2021) book Small Teaching: Interventions that require a major instructional overhaul, even if effective, will not be adopted.

As noted earlier, many intervention studies have weak designs (e.g., no control group) and small sample sizes (e.g., $<20$ per group). Future intervention studies must therefore improve methodologically (Principle 6). Additionally, collaborating with other researchers on multiclassroom efficacy studies is crucial (Principle 8): Beyond increasing statistical power (Principle 6), such efforts can rigorously evaluate the generalizability of intervention effectiveness across educational settings and contexts (as an example, see Fyfe et al.'s, 2021, ManyClasses project involving 38 classrooms, although its focus was not procrastination). Once effective interventions are developed and rigorously validated, their supporting data and materials (e.g., lecture slides, videos, descriptions of the procedure) should be disseminated openly so that interested instructors can evaluate and implement them (Principle 9).

\section{Holistic approach}

Preventing a complex behavioral problem such as academic procrastination is not easy. We therefore advocate for a holistic approach (Principle 4): Instead of taking a single, narrow perspective, our proposed approach introduces multiple small changes that are individually easily implementable (Principle 3) but that jointly cover key facets of academic procrastination (see also Svartdal et al., 2020, for a similar approach). As illustrated in Figure 1, the core of this approach is not to simply "throw the kitchen sink" at the problem, but rather to directly address the key hypothesized causes of procrastination articulated in the process model of self-control (i.e., task-induced negative moods and goal-management failure).

\section{[Insert Figure 1 about here.]}

Also, as shown in the figure, we propose that interventions should promote two contextual factors that are not hypothesized causes of procrastination but should facilitate adoption and maintenance of the intervention practices targeting the causes: a metacognitive factor (reflection) and a social factor (community building). Requiring students to regularly reflect on their study behaviors related to academic procrastination and to make needed adjustments should facilitate the effectiveness of the interventions that more directly target the hypothesized causes. In addition, the likelihood of students' regularly using intervention techniques is likely increased if they have a sense of community and see that the entire class is using the techniques and engaged in reducing academic procrastination.

Certainly, a holistic approach is less common than introducing one specific intervention at a time and testing whether it is effective. This latter approach has scientific merits (primarily, ease of interpretation), but it also has major limitations. For example, an intervention based on a single instructional change often produces a small (often nonsignificant) effect-size estimate, especially when the study is conducted in classrooms (where there is little experimental control) and has a large sample size (e.g., Fyfe et al.'s, 2021, ManyClasses project). The impact of any single, small-change intervention is likely to be small and difficult to detect.

We advocate that interventions for academic procrastination should follow the lead of prevention programs for complex self-regulation problems such as drug abuse, juvenile violence, and risky or abusive sexual behavior (Casey \& Lindhorst, 2009; Nation et al., 2003). Specifically, we advocate starting with a holistic, comprehensive program that targets several dimensions (including teaching methods and social support) and is therefore likely to produce larger effect sizes than a narrow program is. Indeed, individually not-so-effective intervention strategies may show a more robust impact when combined. An approach focusing on one intervention at a time may miss out on such a possibility.

Admittedly, a multipronged approach makes it more difficult to discern which specific intervention techniques are effectively "doing their job," but this challenge can be addressed. First, one may examine whether individual differences in the use of each technique predict procrastination. Such analyses can shed light on the intervention's "active ingredients." Second, once such hypotheses are developed, future studies can selectively 
remove particular techniques from the entire package and examine any effects. Given that the field currently lacks effective intervention methods that can be easily adopted and implemented by instructors, we argue that a multipronged approach is necessary.

\section{Theoretical motivation}

Interventions, even holistic and comprehensive ones, should be guided by theory with sufficient supporting evidence (Principle 5). Despite its simplicity, our process model of procrastination can inform intervention development. Table 2 summarizes our model-based brainstorming and (nonexhaustively) suggests a number of small-change intervention options that instructors can choose from. Note that these methods listed in the table have been generated from the perspective of instructors, because our proposed approach is instructor based and hence requires instructors to choose specific methods and implement them in their classrooms.

\section{[Insert Table 2 about here.]}

Some methods targeting task-induced negative moods are starting rituals, which should help students avoid procrastination by overcoming initial task aversion and simply getting started. For example, the 5-second rule (Robbins, 2017) encourages people to take immediate action toward a goal as soon as the thought to do so occurs; it is based on the idea that if one waits more than $5 \mathrm{~s}$ to initiate a challenging action, it is likely to be abandoned in the face of more pleasurable alternatives. Starting-ritual techniques such as the 5-second rule or the pomodoro technique (see Table 2 for its description), consistently applied, should therefore reduce the likelihood of succumbing to short-term pleasure.

Some methods addressing goal-management failures, derived from social-psychological research, are aimed at increasing the personal value of educational pursuits (e.g., Harackiewicz \& Priniski, 2018) or reducing reliance on "willpower" (e.g., by preemptive removal of known sources of temptations; Vohs \& Piquero, 2021). Writing a short paragraph about why studying some subject or completing some task may be personally valuable (utilityvalue intervention) may address both causes of procrastination hypothesized in our process model simultaneously by reducing task aversion and hence levels of task-induced negative moods and by increasing the perceived importance of academic goals and hence increasing the likelihood that those goals will "win" over short-term pleasure.

Some methods targeting metacognitive (reflection) and social (community building) factors draw on the education literature. Having students reflect on their studying may nudge them toward using better strategies and implementing them more consistently. Such reflections may take the form of exam wrappers, which ask students to reflect on their study behaviors before they see exam results (Lovett, 2013). Developing a sense of community is emphasized in many books on effective teaching (e.g., Lang, 2021) and in prevention research (e.g., Nation et al., 2003): Teaching students about procrastination (via short lectures or videos) and following up with discussions and check-ins supports the shared classroom goal of reducing procrastination.

\section{Objective measures for evaluating interventions}

Finally, we advocate for assessing intervention effectiveness using objective measures (Principle 7), along with subjective-report questionnaires. Although some researchers have used objective measures for decades (e.g., Moon \& Illingworth, 2005; Steel et al., 2001), self-reports have dominated the measurement of procrastination because many researchers believe that it must be differentiated from strategic delay (intentionally putting off work until deadlines approach as a form of motivation) or unintended delay (having work plans disrupted by events out of one's control) and that doing so requires knowing subjects' intentions.

We appreciate this argument, but relying solely on self-reports-especially retrospective reports of intentions - is problematic because people cannot access and accurately report on many of their mental processes and causes of their behavior, especially retrospectively (Nisbett \& Wilson, 1977). Indeed, Kim and Seo's (2015) meta-analysis indicated that self-reports about procrastination are biased and have limited accuracy, and they recommended that "researchers devise alternatives to self-report instruments for indexing procrastination and other variables. Researchers should remember that participants cannot evaluate themselves accurately and may not report honestly either" (p. 32).

Objective measures of academic procrastination are critical for intervention research: Effective interventions should improve students' actual study behaviors. By analogy, psychologists would be rightly dissatisfied by alcoholism interventions that merely reduced patients' ratings of addiction severity without 
affecting their drinking. Behavioral measures are thus crucial to rigorous tests of intervention efficacy that go beyond mere expectancy, placebo, or effort-justification effects.

Educational institutions' increasing reliance on learning management systems (LMSs), accelerated by the COVID-19 pandemic, as well as the recent popularity of massive open online courses, commonly referred to as MOOCs (e.g., Coursera, Udacity), has given researchers access to a rich data set of students' study behaviors (e.g., when they watch lectures, when they open or submit assignments). Using such LMS data, we conducted a classroom individual-differences study of academic procrastination (Gustavson et al., 2022, $N=113$ ). As in some other recent studies (e.g., Cormack et al., 2020; Steel et al., 2018), our objective measure (Fig. 2a) was submission times for various assignments (e.g., quizzes and online experiments, most completed in $<15-25$ $\min )$.

\section{[Please insert Figure 2 about here.]}

As illustrated in Figure $2 \mathrm{~b}$ (data from a weekly reading quiz), submission times for individual assignments were skewed. Later submission times, aggregated across all assignments, predicted not only poorer final numerical course grades $(r=.46)$ but also higher stress levels reported at the end of the semester $(r=-.41)$, as shown in Figures $3 \mathrm{a}$ and $3 \mathrm{~b}$, respectively (the submission times were log-transformed to reduce skewness). These associations were as strong as those based on end-of-semester retrospective self-reports of procrastination. Moreover, in our regression analyses, submission times significantly predicted variance in course grades and stress levels above and beyond the variance predicted by all other individual-differences measures (e.g., conscientiousness, initial interest in the topic). It is important to note that these results persisted even in analyses using submission times from activities only in the first 3 weeks of the course.

\section{[Please insert Figure 3 about here.]}

We acknowledge that assignment submission times are not a "pure" measure of procrastination (no measure is); in particular, they cannot indicate why many students waited (i.e., one cannot tell from submission times by themselves whether the delay in completing assignments really reflected voluntary and irrational decisions). It is important to note, however, that this measurement error resulting from including submission times potentially reflecting strategic or unintended delays did not eliminate their predictive power, as shown in Figure 3. Moreover, this interpretive shortcoming can be easily supplemented by administering a few self-report questions at the time of assignment submissions (to minimize retrospective biases) so that one can better differentiate procrastination from strategic or unintentional delay (e.g., by asking students, before they submit the assignment, whether they planned in advance when to complete it or whether some unexpected or unavoidable events led to a delay in assignment completion).

Objective measures of students' study-related behaviors, such as assignment submission times, are promising for assessing intervention effectiveness; specifically, the distribution following an effective procrastination intervention should be shifted to the left relative to the distribution in Fig. 2b. Moreover, the finding that even early-semester submission times, observed in the first 3 weeks of classes, predicted key outcomes (Gustavson et al., 2022) suggests that they can be used to proactively identify and assist students who might struggle later. Therefore, further examining objective measures of students' procrastination-related behaviors in future classroom intervention studies (perhaps in conjunction with more commonly used selfreport measures) will advance understanding of not only the processes underlying study habits and procrastination behaviors but also how to change them.

\section{Concluding Remarks}

Despite the potential benefits of reducing academic procrastination, intervention studies have been rare. However, by uncovering the predictors, consequences, and potential underlying causes of procrastination, prior research has laid a foundation for developing interventions that can be administered in classroom settings and conducting rigorous intervention studies to test their effectiveness. It will be demanding to design and conduct intervention research in line with the guiding principles listed in Table 1, but this ambitious goal is within reach, through open, collaborative efforts among researchers, instructors, and students. 


\section{Recommended Reading}

Duckworth, A. L., Milkman, K. L., \& Laibson, D. (2018). Beyond willpower: Strategies for reducing failures of self-control. Psychological Science in the Public Interest, 19(3), 102-129. https://doi.org/10.1177/1529100618821893. A broad-scope review of the self-control literature that is especially helpful because it focuses on strategies to reduce self-control failure, many of which are readily applicable to educational settings.

Fyfe, E. R., de Leeuw, J. R., Carvalho, P. F., Goldstone, R. L., Sherman, J., Admiraal, D., Alford, L. K., Bonner, A., Brassil, C. E., Brooks, C. A., Carbonetto, T., Chang, S. H., Cruz, L., Czymoniewicz-Klippel, M., Daniel, F., Driessen, M., Habashy, N., Hanson-Bradley, C. L., Hirt, E. R., . . Motz, B. A. (See References). A report on an impressive study illustrating the power of multiclassroom studies (Principle 8 in Table 1), especially in evaluating the generalizability of a target intervention across settings and contexts.

Lang, J. M. (2021). (See References). A nicely written book that compellingly illustrates the principle of small teaching (Principle 3 in Table 1), provides a framework that can be applied to the classroom, and supports various small-teaching techniques with relevant scientific evidence.

Steel, P. (2011). (See References). A popular-press book that provides a broad overview of procrastination research and its findings and presents Steel's influential temporal motivation theory in a highly accessible manner, with accompanying tips for reducing procrastination based on the "procrastination equation" described in this article.

Stemmle, D. (2021). Procrastination solutions for college students: The underground playbook for overcoming procrastination and achieving peak performance. College Success Academy. A recent self-help book on academic procrastination that is written specifically for college students and provides many useful tips.

Svartdal, F., Dahl, T. I., Gamst-Klaussen, T., Koppenborg, M., \& Klingsieck, K. B. (2020). (See References). An article presenting the case that typical study environments surrounding students are "procrastination friendly" and suggesting possible remedies from the perspectives of both instructors and students.

\section{References}

Benjamin-Pollak, R., Muschinski, L., \& Miyake, A. (2022). The unexamined variability shared between personality and study babits: A commonality analysis of academic procrastination [Manuscript in preparation]. Department of Psychology and Neuroscience, University of Colorado Boulder.

Beutel, M. E., Klein, E. M., Aufenanger, S., Brähler, E., Dreier, M., Müller, K. W., Quiring, O., Reinecke, L., Schmutzer, G., Stark, B., \& Wölfling, K. (2016). Procrastination, distress and life satisfaction across the age range: A German representative community study. PLOS ONE, 11(2), Article e0148054. https://doi.org/10.1371/journal.pone.0148054

Casey, E. A., \& Lindhorst, T. P. (2009). Toward a multi-level, ecological approach to the primary prevention of sexual assault: Prevention in peer and community contexts. Trauma, Violence, \& Abuse, 10(2), 91-114. https://doi.org/10.1177/1524838009334129

Cormack, S. H., Eagle, L. A., \& Davies, M. S. (2020). A large-scale test of the relationship between procrastination and performance using learning analytics. Assessment \& Evaluation in Higher Education, 45(7), 1046-1059. https://doi.org/10.1080/02602938.2019.1705244

Dunlosky, J., Rawson, K. A., Marsh, E. J., Nathan, M. J., \& Willingham, D. T. (2013). Improving students' learning with effective learning techniques: Promising directions from cognitive and educational psychology. Psychological Science in the Public Interest, 14(1), 4-58. https:// doi.org/10.1177/1529100612453266

Frank, T. (2018, November 29). The science behind why you procrastinate [Video]. YouTube. https://www.youtube.com/watch?v=7DvftaHlZR0

Frank, T. (2021, September 28). How to organize your calendar: The ultimate guide [Video]. YouTube. https://www.youtube.com/watch?v=ODXV-fb_c-I

Fyfe, E. R., de Leeuw, J. R., Carvalho, P. F., Goldstone, R. L., Sherman, J., Admiraal, D., Alford, L. K., Bonner, A., Brassil, C. E., Brooks, C. A., Carbonetto, T., Chang, S. H., Cruz, L., Czymoniewicz-Klippel, M., Daniel, F., Driessen, M., Habashy, N., Hanson-Bradley, C. L., Hirt, E. R., . . Motz, B. A. (2021). ManyClasses 1: Assessing the generalizable effect of immediate feedback versus delayed feedback across many college classes. Advances in Methods and Practices in Psychological Science, 4(3). https://doi.org/10.1177/25152459211027575

Gollwitzer, P. M., Wieber, F., Myers, A. L., \& McCrea, S. M. (2010). How to maximize implementation intention effects. In C. R. Agnew, D. E. Carlston, W. G. Graziano, \& J. R. Kelly (Eds.), Then a miracle occurs: Focusing on behavior in social psychological theory and research (pp. 137-161). Oxford University Press. 
Gustavson, D. E., Carruth, N. P., Lurquin, J. H., Zhang, H., Kane, M. J., \& Miyake, A. (2022). Evaluating an objective measure of academic procrastination using submission times in learning management systems [Manuscript in preparation]. Department of Psychology and Neuroscience, University of Colorado Boulder.

Gustavson, D. E., \& Miyake, A. (2017). Academic procrastination and goal accomplishment: A combined experimental and individual differences investigation. Learning and Individual Differences, 54, 160-172. https://doi.org/10.1016/j.lindif.2017.01.010

Gustavson, D. E., Miyake, A., Hewitt, J. K., \& Friedman, N. P. (2014). Genetic relations among procrastination, impulsivity, and goal-management ability: Implications for the evolutionary origin of procrastination. Psychological Science, 25(6), 1178-1188. https://doi.org/10.1177/0956797614526260

Gustavson, D. E., Miyake, A., Hewitt, J. K., \& Friedman, N. P. (2015). Understanding the cognitive and genetic underpinnings of procrastination: Evidence for shared genetic influences with goal management and executive function abilities. Journal of Experimental Psychology: General, 144(6), 1063-1079. https://doi.org/10.1037/xge0000110

Harackiewicz, J. M., \& Priniski, S. J. (2018). Improving student outcomes in higher education: The science of targeted intervention. Annual Review of Psychology, 69, 409-435. https://doi.org/10.1146/annurev-psych-122216011725

Hofmann, W., \& Kotabe, H. (2012). A general model of preventive and interventive self-control. Social and Personality Psychology Compass, 6(10), 707-722. https://doi.org/10.1111/j.1751-9004.2012.00461.x

Huang, N., Zhang, J., Burtch, G., Li, X., \& Chen, P. (2021). Combating procrastination on massive online open courses via optimal calls to action. Information Systems Research, 32(2), 301-317. https://doi.org/10.1287/isre.2020.0974

Kaftan, O. J., \& Freund, A. M. (2019). A motivational perspective on academic procrastination: Goal focus affects how students perceive activities while procrastinating. Motivation Science, 5(2), 135-156. https://doi.org/10.1037/mot0000110

Kim, K. R., \& Seo, E. H. (2015). The relationship between procrastination and academic performance: A metaanalysis. Personality and Individual Differences, 82, 26-33. https://doi.org/10.1016/j.paid.2015.02.038

Klingsieck, K. B. (2013). Procrastination in different life-domains: Is procrastination domain specific? Current Psychology, 32(2), 175-185. https://doi.org/10.1007/s12144-013-9171-8

Krause, K., \& Freund, A. M. (2014). How to beat procrastination: The role of goal focus. European Psychologist, 19(2), 132-144. https://doi.org/10.1027/1016-9040/a000153

Lang, J. M. (2021). Small teaching: Everyday lessons from the science of learning (2nd ed.). Jossey-Bass.

Lovett, M. C. (2013). Make exams worth more than the grade: Using exam wrappers to promote metacognition. In M. Kaplan, N. Silver, D. LaVaque-Manty, \& D. Meizlish (Eds.), Using reflection and metacognition to improve student learning (pp. 18-52). Stylus Publishing.

Miyake, A., \& Friedman, N. P. (2012). The nature and organization of individual differences in executive functions: Four general conclusions. Current Directions in Psychological Science, 21(1), 8-14. https://doi.org/10.1177/0963721411429458

Moon, S. M., \& Illingworth, A. J. (2005). Exploring the dynamic nature of procrastination: A latent growth curve analysis of academic procrastination. Personality and Individual Differences, 38(2), 297-309. https://doi.org/10.1016/j.paid.2004.04.009

Nation, M., Crusto, C., Wandersman, A., Kumpfer, K. L., Seybolt, D., Morrissey-Kane, E., \& Davino, K. (2003). What works in prevention: Principles of effective prevention programs. American Psychologist, 58(6-7), 449-456. https://doi.org/10.1037/0003-066X.58.6-7.449

Nisbett, R. E., \& Wilson, T. D. (1977). Telling more than we can know: Verbal reports on mental processes. Psychological Review, 84(3), 231-259. https://doi.org/10.1037/0033-295X.84.3.231

Peixoto, E. M., Pallini, A. C., Vallerand, R. J., Rahimi, S., \& Silva, M. V. (2021). The role of passion for studies on academic procrastination and mental health during the COVID-19 pandemic. Social Psychology of Education, 24(3), 877-893. https://doi.org/10.1007/s11218-021-09636-9

Perrin, C. J., Miller, N., Haberlin, A. T., Ivy, J. W., Meindl, J. N., \& Neef, N. A. (2011). Measuring and reducing college students' procrastination. Journal of Applied Behavior Analysis, 44(3), 463474. https://doi.org/10.1901/jaba.2011.44-463

Robbins, M. (2011, June). How to stop screwing yourself over [Video]. TED Conferences. https://www.ted.com/talks/mel_robbins_how_to_stop_screwing_yourself_over

Robbins, M. (2017). The 5-second rule: Transform your life, work, and confidence with everyday courage. Savio Republic. 
Sirois, F., \& Pychyl, T. (2013). Procrastination and the priority of short-term mood regulation: Consequences for future self. Social and Personality Psychology Compass, 7(2), 115-127. https://doi.org/10.1111/spc3.12011

Sirois, F. M., \& Giguère, B. (2018). Giving in when feeling less good: Procrastination, action control, and social temptations. British Journal of Social Psychology, 57(2), 404-427. https://doi.org/10.1111/bjso.12243

Steel, P. (2007). The nature of procrastination: A meta-analytic and theoretical review of quintessential selfregulatory failure. Psychological Bulletin, 133(1), 65-94. https://doi.org/10.1037/0033-2909.133.1.65

Steel, P. (2011). The procrastination equation: How to stop putting things off and start getting things done. HarperCollins.

Steel, P., Brothen, T., \& Wambach, C. (2001). Procrastination and personality, performance, and mood. Personality and Individual Differences, 30(1), 95-106. https://doi.org/10.1016/S0191-8869(00)00013-1

Steel, P., \& Klingsieck, K. B. (2016). Academic procrastination: Psychological antecedents revisited. Australian Psychologist, 51(1), 36-46. https://doi.org/10.1111/ap.12173

Steel, P., Svartdal, F., Thundiyil, T., \& Brothen, T. (2018). Examining procrastination across multiple goal stages: A longitudinal study of temporal motivation theory. Frontiers in Psychology, 9, Article 327. https://doi.org/10.3389/fpsyg.2018.00327

Svartdal, F., Dahl, T. I., Gamst-Klaussen, T., Koppenborg, M., \& Klingsieck, K. B. (2020). How study environments foster academic procrastination: Overview and recommendations. Frontiers in Psychology, 11, Article 540910. https://doi.org/10.3389/fpsyg.2020.540910

Tice, D. M., \& Baumeister, R. F. (1997). Longitudinal study of procrastination, performance, stress, and health: The costs and benefits of dawdling. Psychological Science, 8(6), 454-458. https://doi.org/10.1111/j.14679280.1997.tb00460.x

Tice, D. M., \& Bratslavsky, E. (2000). Giving in to feel good: The place of emotion regulation in the context of general self-control. Psychological Inquiry, 11(3), 149-159. https://doi.org/10.1207/S15327965PLI1103_03

Tice, D. M., Bratslavsky, E., \& Baumeister, R. F. (2001). Emotional distress regulation takes precedence over impulse control: If you feel bad, do it! Journal of Personality and Social Psychology, 80(1), 53-67. https://doi.org/10.1037/0022-3514.80.1.53

Urban, T. (2016, February). Inside the mind of a master procrastinator [Video]. TED Conferences. https://www.ted.com/talks/tim_urban_inside_the_mind_of_a_master_procrastinator

van Eerde, W., \& Klingsieck, K. B. (2018). Overcoming procrastination? A meta-analysis of intervention studies. Educational Research Review, 25, 73-85. https://doi.org/10.1016/j.edurev.2018.09.002

Vohs, K. D., \& Piquero, A. R. (2021). Self-control at 220 miles per hour: Steering and braking to achieve optimal outcomes during adolescence. Current Directions in Psychological Science, 30(4), 351-357. https://doi.org/10.1177/09637214211014509

Yang, Z., Asbury, K., \& Griffiths, M. D. (2019). An exploration of problematic smartphone use among Chinese university students: Associations with academic anxiety, academic procrastination, self-regulation and subjective wellbeing. International Journal of Mental Health and Addiction, 17(3), 596-614. https://doi.org/10.1007/s11469018-9961-1

Zacks, S., \& Hen, M. (2018). Academic interventions for academic procrastination: A review of the literature. Journal of Prevention \& Intervention in the Community, 46(2), 117-130. https://doi.org/10.1080/10852352.2016.1198154

Zhang, S., \& Feng, T. (2020). Modeling procrastination: Asymmetric decisions to act between the present and the future. Journal of Experimental Psychology: General, 149(2), 311-322. https://doi.org/10.1037/xge0000643 
Table 1.

Nine Guiding Principles for Intervention Research on Academic Procrastination

\begin{tabular}{lc}
\hline \multicolumn{1}{c}{ Principle } & \multicolumn{1}{c}{ Explanation } \\
\hline $\begin{array}{l}\text { 1. Conduct research in authentic } \\
\text { educational settings }\end{array}$ & $\begin{array}{c}\text { Intervention studies should be conducted in authentic educational settings (e.g., } \\
\text { classrooms) over meaningful durations (e.g., semester), rather than in artificial } \\
\text { laboratory settings with short durations (e.g., 2 weeks). In real classroom } \\
\text { settings, the stakes and students' motivations are higher, and self-regulation } \\
\text { challenges are greater. } \\
\text { Although individual intervention techniques may be relatively simple, establishing } \\
\text { new habits based on those techniques can be challenging. Instructors should } \\
\text { 2. Encourage students to engage } \\
\text { in repeated practice } \\
\text { repeatedly encourage students to keep practicing those techniques until they } \\
\text { become habits. } \\
\text { 3. Adopt a small-teaching } \\
\text { Intervention techniques should be relatively easy to implement in classroom } \\
\text { settings, without prior expertise or extensive training (e.g., training in leading } \\
\text { therapy sessions) and without requiring major changes to syllabi or lesson } \\
\text { plans. }\end{array}$ \\
\hline
\end{tabular}

\section{Underlying philosophy and theoretical basis}

4. Adopt a holistic, multipronged approach

5. Work from a theoretical basis
It is not easy to change well-established habits and complex behaviors. Interventions will more likely succeed if they start from this premise and include a host of small-teaching interventions that target different aspects of academic procrastination. Such a holistic approach should target not only the theoretically hypothesized causes of procrastination but also factors that facilitate behavior change (e.g., students' metacognition, classroom contexts, peer support). Although this holistic approach presents new challenges (e.g., the difficulty of identifying the "active ingredients" of any effective intervention, as well as of designing a suitable control condition in intervention studies), it compensates for them by maximizing effect sizes.

Any intervention technique to be used in a study should be derived from a wellarticulated theory with sufficient supporting evidence.

\section{Research methods and practices}

6. Employ rigorous methodology

Intervention studies should use methodologically sound designs (e.g., including proper control conditions) with sufficient statistical power (e.g., a large enough sample size based on effect-size considerations). In authentic educational settings, conducting a true randomized control study (e.g., assigning students randomly to control and treatment groups) may not always be feasible, but efforts should be made to minimize interpretational problems (e.g., by conducting a multiclassroom study, possibly over multiple semesters, with and without interventions).

7. Go beyond self-reports and include objective measures for assessing intervention effectiveness

8. Scale up for collaborative multiclassroom studies
Academic procrastination is ultimately about students' actual study behaviors, not merely their subjective feelings. Intervention research should not rely solely on self-report questionnaires, especially given their vulnerability to expectancy and placebo effects, as well as serious concerns about people's accuracy in reporting their intentions retrospectively. Self-reports should be supplemented with objective measures of students' behavior, such as assignment submission times. Researchers may explore creative ways to assess students' procrastination-related behaviors and the intentions behind them, without relying exclusively on retrospective reports.

Educational intervention studies are often conducted within a single classroom, which is justifiable at initial method-development and feasibility-testing stages. Once promising interventions are developed, however, it is crucial to scale up and conduct multiclassroom studies, collaboratively with other researchers and 
9. Engage in open-science practices instructors, to properly assess implementation feasibility and generalizability of intervention effectiveness across settings. Although collaborative research increases required time and effort, it is achievable and highly rewarding. The ultimate goal of developing effective interventions is to make positive and broad impacts on educational practices and help students reduce academic procrastination. This requires openly sharing with a broad audience (i.e., researchers, instructors, and students) not only the data for independent evaluation but also the developed intervention materials. Doing so makes replication attempts possible. Open science also requires the results of any intervention studies to be reported in some way, regardless of whether the intervention produced significant results, to minimize the file-drawer problem and thereby avoid inflated effect-size estimates in future meta-analysis. In addition, once promising intervention methods are developed, it is important to preregister the hypotheses and analysis plans for evaluation studies to improve research transparency. 
Table 2.

A List of Potential Small-Teaching Interventions Consistent With Our Process (Self-Control) Model of Academic Procrastination, Categorized by the Cause or Facilitating Factor Targeted

\section{Targeting Hypothesized Cause 1: Task-Triggered Negative Mood States}

- Practicing starting rituals: These techniques target initial resistance that students might feel toward an academic task as a result of task aversion and help them get started on that task. Once they start working on the task, it is likely that they will keep working on it. These techniques are also helpful because they focus students not on the outcome (e.g., delivering a finished product, getting a good score on an upcoming exam) but rather on the process (e.g., a current task at hand), which has been found to be more effective in dealing with procrastination (Kaftan \& Freund, 2019). A challenge is to develop ways to help students practice these techniques consistently so that they remember to apply them when appropriate situations arise.

o Teach students the pomodoro technique: This technique begins with setting a timer to $25 \mathrm{~min}$, starting on the task right away, working in a focused manner for that duration, and then taking a 5-min break; this sequence can be repeated four times before a longer break. The pomodoro technique is a popular and well-known productivity tool, and some good apps gamify this process (e.g., Forest, Seekrtech, http://www.seekrtech.com/en). This technique has an added benefit of enhancing students' focus on the task at hand.

o Teach students the 5-second rule: This rule was initially proposed by Robbins in her TED talk (Robbins, 2011) and subsequently elaborated in her popular book (Robbins, 2017). The rule states, "The moment you have an instinct to act on a goal you must [start counting backwards from 5] and physically move [by the end of that 5-s period] or your brain will stop you" (Robbins, 2017, p. 35). Robbins claims that applying the rule consistently and taking action can have positive impacts on various life domains (e.g., mental health, personal finance), including procrastination. Although the 5 -second rule has not been rigorously tested, this simple idea holds promise.

- Reducing task aversion: Initial task aversion, if strong enough, triggers a need to repair one's negative mood, which leads to seeking short-term pleasure. Thus, reducing students' aversion toward academic tasks is important, and the techniques listed here may be helpful in this regard.

○ Assign utility-value writing exercises: A simple writing exercise in which students reflect on why or how a particular educational activity (e.g., learning statistics, completing a writing assignment) is personally valuable to them has been shown to be an effective social-psychological intervention in classroom settings (see Harackiewicz \& Priniski, 2018, for a review). Although this technique has not yet been applied to academic procrastination, it may reduce initial task aversion and thereby nudge students toward getting started on the task at hand. Note that this technique may simultaneously address the second hypothesized cause in our model by enhancing the personal value students place on their longterm learning goals (see below).

- Break down complex assignments into separate ones: Assignments that require multiple days of work (e.g., writing a term paper) can feel overwhelming and thus elicit the feeling of task aversion. Moreover, the deadlines for such assignments are set well into the future (e.g., a month way), which makes it easier for students to procrastinate (in fact, Svartdal et al., 2020, identified long deadlines as one of the procrastination-friendly study environments). Breaking down a complex assignment into multiple mini-assignments, each with its own deadline (e.g., generating an outline, writing some parts of the paper, completing a full rough draft, revising the final paper), may help students not only reduce procrastination but also produce a betterquality final product.

- Set up an assignment in a way that promotes a process focus (vs. an outcome focus): When students work on a major assignment or exam, their long-term goal may focus on the expected final outcome. Such an outcome focus is associated with greater stress, greater task aversion, and reduced motivation, compared with a process focus (e.g., focus on the next small step one can take to make progress on a bigger task; Kaftan \& Freund, 2019). Teaching students about the importance of process focus may be helpful, and so is presenting an assignment in a way to encourage students to focus on specific processes (e.g., breaking down a complex task into smaller chunks, providing a to-do list for exam preparation). This technique may be particularly helpful if combined with other tools that promote a focus on processes (e.g., the pomodoro technique). 


\section{Targeting Hypothesized Cause 2: Goal-Management Failures}

- Enhancing long-term goals: A critical aspect of the second hypothesized cause of procrastination-goal-management failures - is the self-control dilemma, a conflict between short-term pleasure (e.g., a need for temporary mood repair) and long-term goals (e.g., working on a writing assignment). One way to help students resolve this dilemma in favor of their long-term goals and hence avoid procrastination is to help them increase the personal value they attach to their long-term learning goals.

○ Assign utility-value writing exercises: Utility-value writing exercises (already described above) should enhance the value of long-term goals by clarifying why studying a particular topic or working on a particular assignment is important and worthwhile.

o Teach students how to create goals: Many students do not set specific long-term goals, let alone write them down, so teaching students how to set goals effectively may be helpful, especially if they can commit to these goals and if the goals are effective. Productivity books frequently recommend SMART goals, that

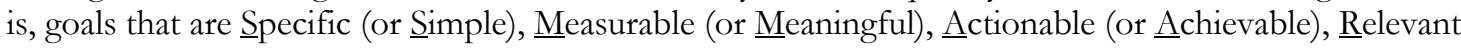
(or Realistic), and Time-bound (or Trackable). Our experience is that students struggle with creating SMART goals (Gustavson \& Miyake, 2017); guidance and repeated practice seem necessary, along with strong commitments from students to strive toward the SMART goals they create.

- Making long-term goals more accessible: Even if students have set goals and know why those goals matter to them personally, they are not useful if they cannot easily access them when they need them. Thus, helping students keep reminding themselves of those long-term goals (as well as specific tasks associated with those higher-level goals) in their everyday lives should facilitate their resolving the self-control dilemma in favor of long-term goals and even minimize the likelihood of facing the self-control dilemma in the first place.

- Teach students about useful planning tools: Many students do not regularly use calendars, to-do lists, reminders, and other useful planning tools (either online or on paper) to keep track of their daily tasks. Teaching students how to use these resources effectively (via either short lectures or useful videos available on the Internet, e.g., Frank, 2021) should improve goal accessibility. (Thomas Frank's website, called College Info Geek, https://collegeinfogeek.com, also provides various useful resources covering all aspects of students' academic lives.) Moreover, encouraging students to plan in advance when to work on which academic tasks and to mark those study sessions in their calendars (with reminders) may be helpful.

- Send students timely and well-crafted reminders: Students should eventually learn how to keep track of assignments and other academic tasks on their own. In the meantime, however, instructors may assist this process by strategically sending out timely reminders, especially early in the semester. Ideal reminders make clear what students are expected to do by when and are written in an encouraging manner (they may also include direct links to the assignments). Learning management systems allow instructors to send out reminders to only those students who have not yet completed an assignment. Recent research provides some suggestions as to what sort of information should be included in such reminders. For example, results of one large-scale study (Huang et al., 2021) suggest that including the assignment completion rate (e.g., " $62 \%$ of the students have completed this assignment") may be helpful.

- Dealing with temptations and distractions: Goal-management failures (i.e., resolving the self-control dilemma at hand in favor of short-term pleasure) are more likely to occur if the study environment has many potential temptations and distractions. Thus, another way to reduce the likelihood of goal-management failures and hence academic procrastination is to reduce the impact of temptations and distractions surrounding students.

- Teach students to create implementation intentions: Implementation intention is a self-regulatory tool used to help turn an intention (e.g., to reach a long-term goal) into an action. It takes the form of an "if-then" rule that describes the specific action to take if a certain situation arises (e.g., "When I finish eating dinner, I will start working on a weekly quiz right away"). This simple rule-creation technique has been often used to promote desirable (but potentially unpleasant) health behaviors involving some degree of self-control (e.g., dieting), but it should also be applicable to the academic domain. Tips for maximizing the potential benefits of implementation intentions are available from the technique's developer, Gollwitzer (see Gollwitzer et al., 2010). Knowing exactly what to do and when should help students minimize the impact of potential distractions and temptations.

- Challenge students to preemptively remove sources of temptations: Self-control research has revealed two approaches to deal with temptations: (a) exerting willpower after one encounters a temptation and (b) preemptively removing potential sources of temptations (Hofmann \& Kotabe, 2012). The latter is a more effective approach to resisting temptations and getting sidetracked by them (e.g., Vohs \& Piquero, 2021). Teach 
students about preventive strategies for self-control (possibly via in-class discussions) and challenge them to implement these strategies in everyday situations. For example, the most common sources of distractions reported by students are their electronic devices, such as smartphones, computers, and tablets. Possible preventive strategies for students to reduce distractions due to electronic devices include (a) leaving their smartphones in a different room while studying, (b) turning on the "do not disturb" mode to block notifications, (c) closing all nonessential browser windows while studying, and (d) using a program that blocks distracting apps and websites while studying (e.g., Freedom, https://freedom.to).

\section{Targeting Contextual Factors That Facilitate Behavior Change}

- Encouraging reflection (metacognitive factor): Although this factor does not directly address the two causes of procrastination hypothesized in our process model, it is nevertheless potentially important because successfully implementing procrastination-reducing strategies and turning them into habits likely requires regular reflection on one's own progress. Providing opportunities for such reflection is likely to help enhance the effectiveness of the specific intervention methods discussed above.

o Regularly ask students to evaluate their study habits: Although it is easy to recommend techniques to students, it is not easy for students to implement them effectively and habitually. Check in with students regularly (e.g., every 3-4 weeks) and ask them to reflect on their progress (e.g., what is working, what is not, what changes they want to implement).

o Administer postexam exam wrappers: Ask students to reflect on how they studied for an exam right before they see their scores (see Lovett, 2013, for the rationale behind administering exam wrappers and some concrete examples). To address procrastination, focus students' reflections on the extent to which they crammed for the exam and on possible ways to avoid cramming for the next exam.

- Building community (social factor): As any instructor knows, classroom climates really matter for students' motivation and engagement. Simply administering the simple intervention techniques outlined above in a vacuum, without engaging students in this "fight against procrastination" effort in some way, seems to be missing some important (and potentially crucial) element for success. Thus, we advocate for including some community-building and peer-support activities to engage students and motivate them to work together to reduce procrastination.

- Teach students about academic procrastination: Most students do not know how procrastination occurs and what can be done to reduce it. Teaching them about procrastination in classroom settings (via brief lectures or Internet videos; e.g., Frank, 2018, and Urban, 2016), especially if combined with in-class discussions, should help develop an antiprocrastination culture. In fact, the simple process model outlined in this article is easy to convey, and students resonate to the model's explanation of how procrastination occurs. It provides a useful starting point for engaging students in classroom discussions (e.g., jointly generating possible ways to tackle procrastination).

- Make "fight against procrastination" a classwide effort: In addition to teaching students about academic procrastination, share with the class some relevant statistics about their progress. For example, provide a weekly report of the percentage of students who completed assignments reasonably early (e.g., > $24 \mathrm{hr}$ before deadline) and encourage (if not reward) the class to beat this average for the next assignment.

- Engage students in small-group activities: Some of the activities discussed in this table (e.g., creating goals and implementation intentions, reflecting on progress) can be done in small groups. Also consider introducing an "accountability partner" system (although knowing how to pair up students can be challenging).

- Gamify efforts to reduce procrastination: Introduce some fun elements to the classwide effort to fight against procrastination. For example, student groups can compete against each other to see which has the earliest average completion time for an assignment.

Note: Each small-teaching (small-change) intervention on this list is framed from the perspective of instructors, not students, but interested student readers should also benefit from this list. Moreover, this list is not intended to be exhaustive, and the individual intervention methods listed here are generated from the perspective of our simple process (self-control) model of procrastination described in the main text and from some of the guiding principles for our proposed approach to developing interventions for academic procrastination (especially the small-teaching and holisticintervention principles, Principles 3 and 4 in Table 1). We encourage interested readers to do their own brainstorming and generate additional possible small-change interventions. For a complementary proposal focusing on changing students' procrastination-friendly study environments in a holistic manner, see Svartdal et al. (2020). 


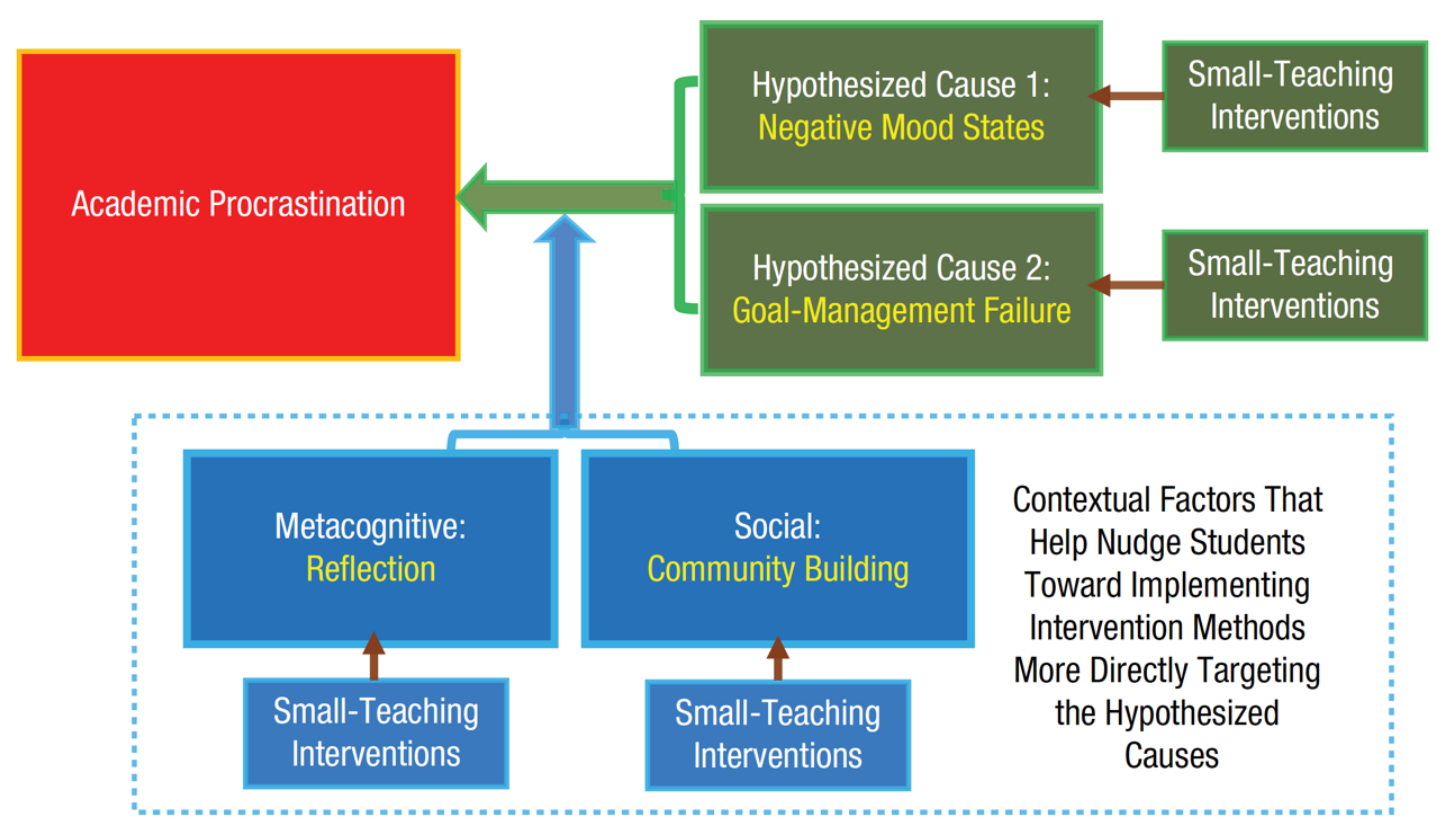

Fig. 1. A schematic illustration of our proposed approach to intervention studies targeting academic procrastination, based on the idea that academic procrastination is multifaceted and is not easy to change with a single, narrow-focused intervention. We propose to reduce academic procrastination by addressing multiple facets associated with academic procrastination both directly and indirectly. Some small-change interventions should directly target the main causes of academic procrastination hypothesized in one's model. As shown here (the dark-green boxes), in our model these causes are negative mood states triggered by impending tasks and the resulting goal-management failures (i.e., choosing immediate pleasure over long-term goals). In addition, we advocate for addressing broader metacognitive and social contexts that indirectly contribute to academic procrastination (the blue boxes). Specifically, we argue that asking students to regularly reflect on their efforts to reduce procrastination (e.g., what is and is not working, what changes to implement for improvement) - is important in facilitating the effectiveness of the interventions that more directly target the hypothesized causes. It is also important to target social contexts surrounding students' efforts to reduce procrastination, through community building, which helps motivate them to change their behavior. A host of specific small-change intervention options that interested researchers and instructors can employ in their research and teaching are discussed in the Theoretical Motivation section. 
a

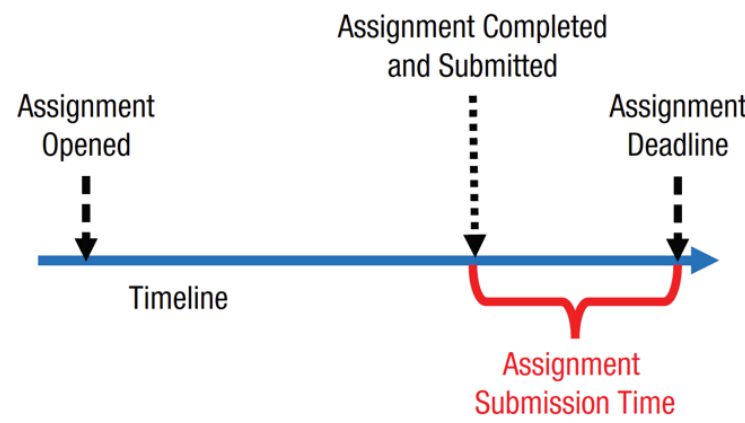

(How Many Days Before the

Deadline the Assignment Was

Submitted)

b

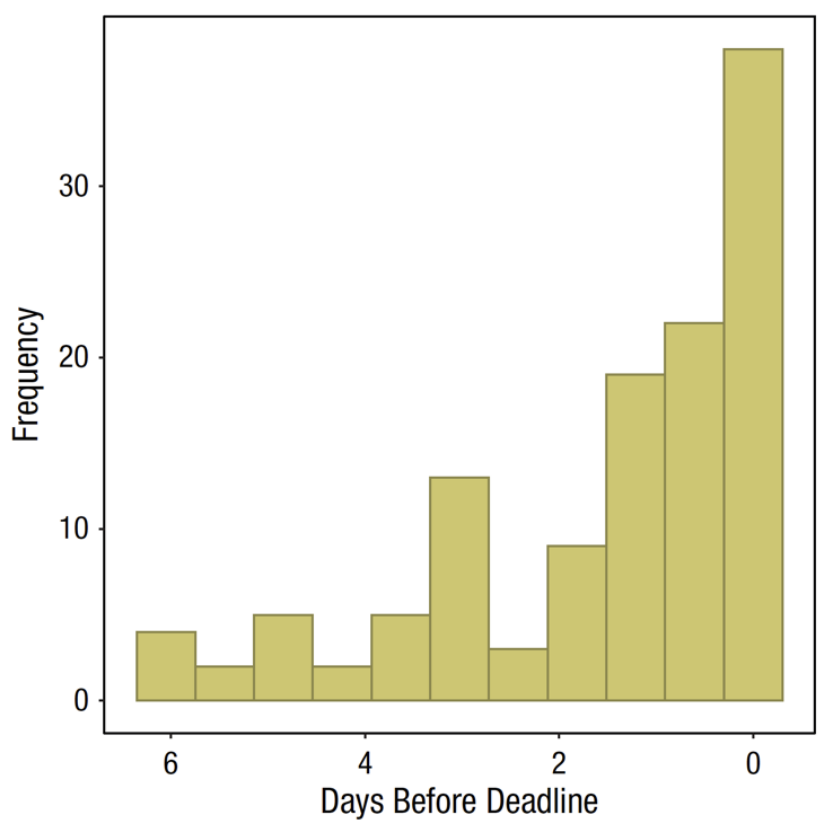

Fig. 2. Visual illustration of the objective measure of students' study behavior-assignment submission times (collected via a learning management system)—used in a recent individual-differences study (Gustavson et al., 2022). The timeline in (a) illustrates how assignment submission time was measured; specifically, it was operationalized as the number of days before the deadline that the assignment was submitted. For example, the submission time of 2.67 days means that the assignment was completed well before the deadline, whereas the submission time of 0.06 days means that it was completed right before the deadline. The graph in (b) is an example of what a typical distribution of submission times would look like for a single assignment (in this case, one of the weekly quizzes on reading assignments). Perhaps not surprisingly, the distribution is highly skewed: Although some students completed the online quiz early, many students tended to wait until near the deadline. 

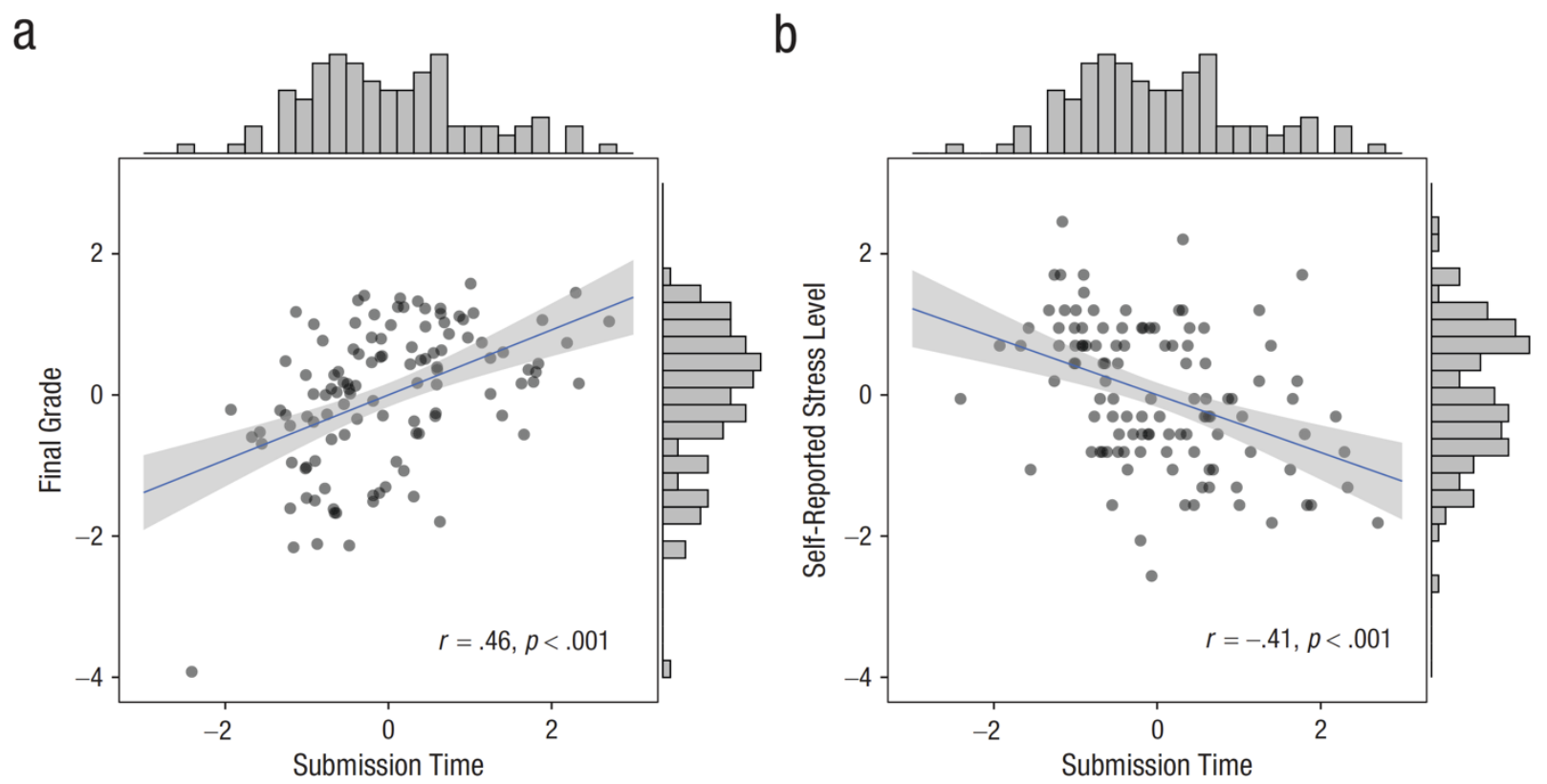

Fig. 3. Scatterplots of the correlations between assignment submission time (aggregated over multiple assignments administered over the semester) and two key outcome measures in the individual-differences study of academic procrastination discussed in the main text (Gustavson et al., 2022, $N=113$ ). The histograms represent the frequency distributions of scores for each variable. Assignment submission times were first log-transformed to reduce the skewness (cf. Fig. 2b) and then standardized (by computing ₹ scores) so that 0 represented the sample mean; smaller values (more negative $z$ scores) indicate submission closer to the deadline (i.e., students who tended to submit assignments close to the deadlines are represented on the left side of the $\mathrm{x}$-axis). The outcome measures (both standardized $z$ scores) are (a) the final numerical course grade (scale from 0 to 100) and (b) the self-reported level of stress, assessed at the end of the semester with five questionnaire items that asked students to retrospectively report their stress levels near deadlines (e.g., 1-2 days before the term-paper deadline, $0-1$ days before the deadline for each weekly chapter quiz). 